\title{
The Effects of Logistic Management on Enterprise Performance: A Case of Gas Depot Atem in Yaounde Cameroon
}

\author{
Francis Mbah Takwi, Atem Atabongfua Mavis \\ Faculty of Business Management and Sustainability, Information and Communication Technology University USA, Yaounde, Cameroon
}

Email address:

francis.takwi@ictuniversity.org (F. M. Takwi), atem.atabongfua@ictuniversity.org (A. A. Mavis)

\section{To cite this article:}

Francis Mbah Takwi, Atem Atabongfua Mavis. The Effects of Logistic Management on Enterprise Performance: A Case of Gas Depot Atem in Yaounde Cameroon. American Journal of Operations Management and Information Systems. Vol. 5, No. 3, 2020, pp. 41-48. doi: 10.11648/j.ajomis.20200503.12

Received: September 6, 2020; Accepted: September 25, 2020; Published: September 29, 2020

\begin{abstract}
In a global economy, competitive and dynamic environment, logistics managements is an important strategic factor for increasing competitiveness. The significance of logistics management had evolved from a more passive and cost minimization oriented activity to a key success factor for firm competitiveness. There was therefore an emerging consensus about the need for companies to handle logistics issues together with economic and business issues. The performance of logistics systems was typically related to delivery service, logistics cost and tied up capital. Customers increasingly expected shorter delivery times and more accurate services and logistics management was perhaps most easily conceptualized in a third party logistic service provider like Gas Depot Atem. The study also looked at the effect of the logistics performance as the moderating variable on the relationship between logistics management and the firm Performance. The specific objectives of the study were to examine the influence of transport management on firm performance, evaluate the influence of inventory management on firm performance, examine the influence of order processing on firm performance, establish the influence of information flow on firm performance, and evaluate the moderating effect of logistics information system on the relationship between the logistics management and firm performance. The study used both descriptive and explanatory research designs. The target population for this study was the workers of Gas Depot Atem (about a 100). Our sample was about 40 workers of gas depot. A semi-structured questionnaire was administered through the e-mail survey and hand delivery. Secondary data was obtained from both published and unpublished records. The questionnaire was tested for validity and reliability. Both quantitative and qualitative techniques were used to analyses the data with the assistance of SPSS software program version 22. The study found that transport management; inventory management; order process management and information flow management were individually predictors of firm performance with inventory management being the most significant predictor. The study concludes that logistics management has the potential of positively influencing performance on firms in terms of cost reduction, timely delivery, reduced lead time, demand realization, increased market share, quality products and customer service satisfaction. Consequently, this study provides firms' managers with insights of how firms can develop a competitive edge through the implementation of logistics management. This study therefore, recommends that factors associated with logistics management need to be considered by firms in their performance strategic plans as they have significant impact on performance.
\end{abstract}

Keywords: Logistics, Supply Chain, Performance, Competitive Advantage, Effectiveness

\section{Introduction}

Logistics has gone from being a military matter to being one of the key business issues today. The underlying factor to this situation is, in fact, that logistics is a cross-functional subject, cutting across functional boundaries. Logistics is the work required to move and position inventory throughout a chain of participants. From initial purchase of material or component, the system of logistics adds value by moving inventory when it is needed and where it is needed. Materials and components gain value at each step of their change into 
finished inventory. A basic definition of logistics is as follows:

"Logistics is the process of strategically managing the procurement, movement and storage of materials, parts and finished inventory and related information flows) through the organization and its marketing channels in such a way that current and future profitability are maximized through the cost-effective fulfilment of orders."

Logistics management is the governance of supply chain functions. Logistics management activities typically include inbound and outbound transportation management, fleet management, warehousing, materials handling, order fulfillment, logistics network design, inventory management, supply/demand planning, and management of third party logistics services providers. To varying degrees, the logistics function also includes customer service, sourcing and procurement, production planning and scheduling, packaging and assembly. Logistics management is part of all levels of planning and execution strategic, operational and tactical. It is an integrating function, which coordinates all logistics activities, as well as integrates logistics activities with other functions including marketing, sales manufacturing, finance, and information technology.

Companies must recognise that the competition today is through their capabilities and competencies. By managing their core processes better than competitors manage theirs, organisations can create superior value for customers and consumers. Logistics best practise is presented as a work in progress, subject to a continuous change based on the evolving nature. With the use of logistics management the goal is to link the marketplace and the operating activity business in such way that customers are serviced at higher levels and at a lower cost. If an organisation can perform these activities in a more cost-effective way than the competitors, the organisation will gain the advantage at the marketplace.

\subsection{Statement of the Problem}

In many emerging economies especially in Cameroon, manufacturing industry had been the economic growth engine and was the major tradable sector in those economies. Operation management practices have changed in organizations in the recent past which necessitates organizations to look for alternatives in the strategic operational management [4]. Logistics plays key role in supporting organizations as they strive for more efficient management systems [15] as in the business practices, the inefficient logistics system together with the inefficient internal management would disable the organization to respond to the needs of customers with the lowest price at the shortest feasible time frame including the quality level which does not meet customer expectation and would lead the organizations to the competitive disadvantage situation in the market.

In the past the goals of logistics were connected primarily to cost effectiveness. Nowadays, besides cost effectiveness, attention is paid also to fast lead times and developing customer service. As a result of costs, the price is still an important factor in competition, but in addition companies want shorten delivery times, increase the speed of distribution and reaction, make sure that the delivery arrives on time. Logistics is not just "save money" action; it is an important part of customer oriented service strategy. [14] Logistics management is a supply chain management component that is used to meet customer demands through the planning, control and implementation of effective movement and storage of related information, goods and services from origin to destination. Logistics management helps companies reduce expense and enhance customer service [13].

Logistics plays key role in supporting organization as they strive for more efficient management system [4] as in the business practices, the efficient logistic system together with the inefficient internal management would disable the organization to respond to the needs of the customers with the lowest price at the shortest feasible time frame including the quality level which does not meet customer expectation and would lead the organization to a competitive disadvantage situation against their rivals.

Previous studies had tended to focus more on the developed world [13]. Evidence showed that cultural, social, economic and environmental aspects of each country influenced the link between logistics management and performance agreed that the findings of US firm could not represent the universe of companies nor could findings be generalized to other countries. To add, Developed countries as Europe, America and part of Asia had more developed infrastructure and business structures that easily supported the implementation of logistics as opposed to developing countries [10]. The effort to achieve generalization of the causal relationship between logistics management and performance of logistic firms called for empirical confirmation in diverse environments, especially developing economies such as Cameroon. This study therefore intended to empirically examine how transport management, inventory management, warehouse management, ordered process management and information flow management influenced performance of manufacturing firms in the Cameroon setting.

\subsection{Research Objectives}

\subsubsection{Main Objective}

The purpose of this study was to examine the influence of Logistics management on performance of Gas Depot in Yaoundé Cameroon.

\subsubsection{Specific Objectives}

To achieve the broad objective above, we consider the following specific objectives.

1) To analyze the influence of transport management on performance of Gas Depot in Yaounde Cameroon.

2) To evaluate the influence of inventory management on performance of Gas Depot in Yaounde Cameroon.

3) To establish the influence of information flow management on performance of Gas Depot in Yaounde 
Cameroon.

4) To evaluate the moderating effect of logistics information system on the logistics management on performance of Gas Depot in Yaounde Cameroon.

\subsection{Research Questions}

1) What is the effect of transport management on performance of Gas Depot in Yaounde Cameroon?

2) What is the effect of inventory management on performance of Gas Depot Yaounde Cameroon?

3) To what extend does information flow management affect performance of Gas Depot in Yaounde Cameroon?

\section{PRESENTATION OF THE ORGANIZATION}

Gas Depot ATEM ltd was founded by elite of Lebialem from the North West Region of Cameroon by the name Alewinguoh Beatrice Atem in 2017 as Gad Dopot. Since its inception, Gas Depot functioned as a retail Company. With an initial capital of 1750000 FCFA with a total number of 60 gas bottles with gas inside and later increased to 170 gas bottles with gas making a capital of 4080000 FCFA in 2019. Gas Depot ATEM today is running with a capital of 6720000 with over 3 years of experience in the business management, finance and other fields. The Depot Gas slogan of "we supply what we receive efficiently and effectively" brings up the way they do things to create comfort, provide convenience and an enjoyable atmosphere for their clients internal and external) as well as for their stakeholders. For example, there are no service barriers between their customers, subordinates and top management, and they encourage smart and lean processes that increase service delivery.

Moreover, they focus on their mission and behavior in all that they do.

The Gas depot expects to expand their business in the coming years to meet the needs and expectations of customers, as well as to fulfill their vision of opening many Gas Depot in Yaounde, and Buea.

The Gas Depot makes it possible for the general public to benefit from not only receiving services they pay for, but also taking gas on credit and at times give a different type of gas bottle to his customer when there is not the one he came with, and gives the bottle with a written note, and this bottle exchange varies with the bottle given. You can't give a bottle which is not too popular, $\mathrm{n}$ expect to be given a popular one. This is because if done so, the customer might go with the bottle never to come back.

\section{Literature Review}

\subsection{Logistics Management}

In today's highly competitive environment, many companies are striving to gain a share of the global market and to take advantage of higher production and sourcing efficiency. A key determinant of business performance nowadays is the role of logistics management functions in ensuring the smooth flow of materials, products and information throughout the company's supply chain [12]. Due to the trend of nationalization and globalization in recent decades, the importance of logistics management has been growing in various areas. For firms, logistics management helps to optimize the existing production and distribution processes based on the same resources through management techniques for promoting the efficiency and competitiveness of enterprises [21].

Logistics management plays an important role of adding competitive advantage to a firm in customer support and business excellence. Effective logistics management provides the right product in the right place at the right time that is why it has received much attention over the past decade from practitioners and government. Realizing the importance of sustainability in logistics management it is critical for competitive advantage because operational performance has a positive impact on company's financial performance.

In business, sustainability is defined as a capability to possess and hold continuous competitiveness. However, for logistics management to be considered contributing to a firm's performance, logistics performance needed to be measured [10]. In their study [5] confirmed that, due to increasing awareness of logistics management implications in firm performance and growing awareness of the benefits of leveraging logistics to increase customer value, measuring of performance of logistics had become a high priority. According to [10], there were at least three basic reasons why a firm would want to measure logistics performance: firms could reduce operating costs, use these measures to drive revenue growth, and hence enhance shareholder value. $\mathrm{He}$ continued to say, by measuring operating costs, a researcher could identify whether, when and where to make operational changes to control expenses and very importantly, point out areas for improved asset management.

Even valuable customers could be attracted and retained by improving the price value relationship of products offered through cost reductions and service improvements. Finally, returns to stockholder investments and the market value of the firm could have been significantly impacted

by logistics performance improvements working through the processes that led to share price and dividend policy. This study has therefore considered logistics performance as an intervening variable to logistics management on influencing firm performance. The study concentrated on evaluating the influence of logistics management core activities (transportation, inventory, order processing and information flow on the firm performance in Cameroon. This research focused on forward logistics rather than reverse logistics (which refers to the activities involved in customers returning goods) and analyzed both physical activities and nonphysical activities that were transportation, Inventory management, order processing and information flow as independent variables whiles logistics performance acted as intervening variable.

\subsection{Firm Performance}

In order to understand firm performance it was prudent to 
first understand what performance measurement was all about since it was through performance measurement that firm performance could be realized. According to [18], Performance measurement is a crucial criterion for evaluating the competence and achievement of an organization. [22] defined performance measurement as -the process of quantifying action, where measurement is the process of quantification and action leads to performancell. They emphasized the importance of satisfying customer requirements with greater efficiency and effectiveness than the competitors. Here the effectiveness referred to the extent to which customer requirements were met, largely with the essence that customer was always right and the efficiency referred to the measurement as to how economically the firm's resources were utilized (i.e. total output against total input) to provide a specific level of customer satisfaction.

In clarifying the multidimensional relationship between logistics management and firm performance, a clear definition of firm performance was required. According to [19], firm performance encompasses three specific areas of firm outcomes: financial performance (profits, return on assets, return on investment); market performance (sales, market share); and, customer satisfaction/value added [19]. Firm performance comprised the actual output or results of an organization as measured against its intended outputs (or goals and objectives), it involved the recurring activities to establish organizational goals, monitor progress toward the goals, and make adjustments to achieve those goals more effectively and efficiently. [19]

There happened to be at least three basic reasons why a firm wanted to measure logistics performance, firms reduce operating costs, use these measures to drive revenue growth, and hence to enhance shareholder value [10]. Measuring operating costs could identify whether, when and where to make operational changes to control expenses, point out areas for improved asset management and could attract and retain valuable customers by improving the price value relationship of products offered through cost reductions and service improvements. Finally, returns to stockholder investments and the market value of the firm could have be significantly impacted by logistics performance improvements working through the processes that led to share price and dividend policy [10].

Starting in the 1980 s, firms viewed time as a source of competitive advantage, based upon the observation that firms were competing effectively in time tended to excel at improving quality, understanding evolving customer needs, exploiting emerging markets, entering new businesses, and generating new ideas and incorporating them into innovations. Thus, firms started to focus on eliminating waste in the form of time, effort, defective units, and inventory in distribution systems [17]. In fierce time and quality-based competition, logistics capabilities become critical. In fact, many firms - particularly those operating in commodity or convenience goods markets - succeed as a result of their logistics systems, rather than innovation.
Most firms used to achieve these goals through engaging with advanced technologies and production practices such as worker empowerment, just in time ( JIT) and concurrent engineering [7]. However, [6] reported that latest development in industry come out with new dimension which diverted the focus of production performance towards logistics/supply chain capabilities to obtain quality, cost, and delivery, innovation and responsiveness goals.

\section{Methodology}

\subsection{Research Design}

The study adopted both descriptive and explanatory research designs. On one hand, descriptive research design combined with graphical illustrations was used to describe various variables of interest. On the other hand, explanatory research design has been used to establish the magnitude, direction and significance of various logistic management factors on performance of logistic firms in Cameroon. The focus of the research in this paper is the logistics management and the relationship between the application of appropriate logistics management practices in the companies and reducing costs, and thus increasing the efficiency and results of companies' operations and at the same time, strengthening their competitive position on the market.

There are two types of approaches for data analyses which are deductive and inductive, where deductive is for quantitative analysis and inductive is for qualitative analysis. Our study will follow the deductive approach to modeling a framework for the performance of Gas Depot and their survival factors in order to avoid their failures. This approach also made it possible to measure the extent to which these problems affect the survival of Gas Depot and their growth.

\subsection{Sample and Sampling Technique}

The target population for the study are the Gas Depot employees of 100 employees. The sample design for this study is a probability sampling where inclusion criteria consists of managers, owners and workers of Gas Depot in selected district of Mfoundi Division of the center region of Yaounde consisting of yaounde 6 and 3. To this effect, the Mfoundi division is stratified into the different municipality? The municipality of Yaounde 6 and 3 are purposively chosen to represent the population of Gas Depot in the center region of Cameroon. The choice of these municipalities is influenced by the accessibility of the target population and equally the huge presence of majority of Gas Depot operators within the Mfoundi division.

Hence we have made used of non-profitability sampling procedure because the purpose of this study is explanatory. Moreover, stratified random sampling which is a part of profitability sampling is used where the population is divided into strata (or subgroups) and a random sample is taken from each subgroup. A subgroup is a natural set of items. Subgroups might be based on company size, gender or occupation. A sample size of 40 respondents was drawn from 
the population of Gas Depot employees. The questionnaires were distributed to the employees in Gas Depot in Yaounde.

\subsection{Pilot Test}

A pilot study was administered in order to test for validity, reliability and practicability of the research instruments. The most important issue in the research is to ensure reliability and validity. [9] defines reliability as: "The extent to which results are consistent over time and an accurate representation of the total population under study is referred to as reliability and if the results of a study can be reproduced under a similar methodology, then the research instrument is considered to be reliable". According to [2], validity refers to the extent to which a test measures what it is supposed to measure and the extent to its truthfulness, accuracy, authenticity, genuineness, or soundness, whether the means of measurement are accurate and whether they are actually measuring what they are intended to measure. Lastly, the practicability characteristics of instrument can be judged in terms of economy, convenience and interpretability: economy considers trade-off between an ideal research project and what the budget can afford convenience test suggests that the measuring instrument should be easy to administer and interpretability consideration is especially important when persons other than the designers of the test are to interpret the results. Pilot study is therefore used to pretest the constructs to be used in the analysis with the aim of reducing measurement errors, improving validity of the construct measurement and identifying problems in the design and layout of the questions. Following the recommendation by [16], the study randomly selected 10 Gas Depot (10 percent) of the firms for pilot study. The researcher administered the questionnaires to the head of logistics department of the 10 Gas Depot in order to solicit responses for various questions. Once the data was collected, coding and entering into the computer was the next step. Once the data was coded the researcher conducted preliminary analysis to test for reliability using Cronbach's alpha. Cronbach's alpha is known as a good measure of reliability [16]. Its values ranges from 0 to 1 with Cronbach's alpha values between 0.8 and 1.00 indicating a considerable reliability, values between 0.70 and 0.80 indicate an acceptable reliability while values below 0.70 are considered less reliable and unacceptable. The results from reliability analysis aided to suggest whether questionnaire should be reformulated or not. To ensure the validity of the research instrument, the researcher also consulted experts in the area of logistics management and will adjust the questionnaire where necessary.

\subsection{Data Collection}

Primary data was collected and obtained from the distributed questionnaires. This study depended on the primary data because it helps to investigate about what is happening on the ground and also to suggest helpful findings and recommendations. The data was collected using a questionnaire administered by the researcher and a research assistant. The initial section of the questionnaire contained a declaration on confidentiality, a brief statement on the study purpose; as well as an assurance that all data provided was for academic purposes only. The second section of the questionnaire captured the respondent demographic characteristics such as age group, occupation, and gender. The last section of the questionnaire comprised of a set of questions/measurement items under five sub-sections to represent each of the five study variables and corresponding latent constructs.

\section{Presentation of Results and Discussion}

The study was conducted in 40 Gas Depot in the Republic of Cameroon The questionnaire was distributed to 40 important stakeholders linked to logistics function in the organization, employed in these companies. Based on respondents' answers to the questions related to the four important components in logistics -inventory, transportation, storage and information, the effectiveness of the logistics management was determined and whether it leads to increased efficiency or reduction of waste in the company.

\subsection{Influence of Transport Management on Firm Performance}

The study sought to investigate the effect of transport management on performance. Regression analysis was done with firm performance as the dependent factor and capital transport management as tested predictor factor. Data from 40 respondents were tested. The results are illustrated in Table 1.

Table 1. Relationship between Transport Management and Performance.

\begin{tabular}{llll}
\hline Performance & Coefficient & Std. Error & t \\
\hline Transport Management & 3.092 & .224 & 13.794 \\
Constant & .215 & .060 & 3.564 \\
\hline
\end{tabular}

$\mathrm{F}=12.701, \mathrm{P}<0.05, \mathrm{R}^{2}=0.251, \mathrm{R}^{2}$-Adjusted $=0.231$.

The value of variance $\mathrm{R} 2=0.251$, shows that $25.1 \%$ of the firms operating performance is explained by transport management. The values of $\mathrm{F}=12.701, \mathrm{P}<0.05$, shows that transport management statistically and significant predicts the firms performance (i.e., the regression model is a good fit of the data) and that transport management significantly influence the performance of the Gas Depot in Yaounde Cameroon. The value of transport management is statistically significant $(\mathrm{t}=13.794, \mathrm{p}<.05)$. The regression model explaining the results in Table 1 is given by:

$$
\text { Performance }=3.092+0.215 \times \mathrm{TM}
$$

The model shows that transport management positively affects the firm's performance, i.e. an increase in mean index of transport management increases the performance of the company by a positive unit mean index value of 0.215 . The study sought to establish the effect of transport management 
as a function of logistics management on the performance of Gas Depot in Yaounde Cameroon. Numerous studies have posited that well managed transport management lead to improvement of the performance of firms in financial and non-financial fronts.

The study sought to investigate the effect of transport management on performance. Regression analysis was done with firm performance as the dependent factor and capital transport management as tested predictor factor. This study found a positive, significant impact on the hypothesized relationship between financial stress and worker's performance. The findings also conforms to the study done in developed countries by $[1,11,8]$, which defines transport management as an important natural piece of logistics and therefore a vital factor in influencing firm performance. It supports the findings of [21] that transport management was the most important economic activity among the components of business logistics system and do influence firm performance.

\subsection{Influence of Inventory Management on Firm Performance}

The study sought to investigate the relationship between inventory management and performance on Gas Depot in Yaounde Cameroon. The findings are presented in Table 2.

Table 2. The Relationship between Inventory Management on Firm Performance.

\begin{tabular}{llll}
\hline Performance & Coefficient & Std. Error & T \\
\hline Inventory Management & .126 & .170 & .738 \\
Constant & 3.308 & .729 & 4.537 \\
\hline
\end{tabular}

$\mathrm{F}=.544, \mathrm{P}>0.05, \mathrm{R}^{2}=0.014, \mathrm{R}^{2}$-Adjusted $=-0.012$

The value of variance $\mathrm{R}^{2}=0.014$, shows that $1.4 \%$ of the firms operating performance is explained by inventory management. The values of $\mathrm{F}=.544, \mathrm{P}>0.05$, shows that inventory management does not statistically and significant predicts the firms performance (i.e., the regression model is a bad fit of the data) and that inventory management does not significantly influence the performance of Gas Depot in Yaounde Cameroon. The value of inventory management is statistically significant $(\mathrm{t}=.738, \mathrm{p}>0.05)$. The regression model explaining the results is given by: Performance $=3.308+.126 \times$ IM

The model shows that inventory management positively affects the firm's performance, i.e. an increase in mean index of inventory management increases the performance of the company by a positive unit mean index value of 0.126 . The study pursued to establish the influence of inventory management on the performance of Gas Depot in Yaounde Cameroon. The study outcome signified that addition of inventory management to Gas Depot functions has positive impact on firm performance. Results of regression analysis indicate that there is no significant relationship between inventory management and firm performance; $\mathrm{p}>0.05$ $(\mathrm{P}=.465)$. The values of $\mathrm{F}=.544, \mathrm{P}>0.05$, shows that inventory management statistically and significant does not predict the firms performance (i.e., the regression model is not a good fit of the data) and that inventory management does not significantly influence the performance of the Gas Depot in Yaounde Cameroon. The value of inventory management is statistically significant $(\mathrm{t}=.738, \mathrm{p}>.05)$.

Therefore, the null hypothesis "inventory management does not significantly influence firm performance" was accepted. The results of the analysis revealed that the influence of inventory management on firm performance is not significant and is propelled by activities such as just in time, inventory control, cycle counting, and automated recording and inventory management systems.

The results of the present study suggest that inventory management has a significant negative impact on performance. These findings are not in agreement with the study done by [20] that inventories is "a vital part of business," as they are necessary for operations and they also contributed to customer satisfaction. Prior research had provided same empirical support that inventory management was important to business and vital to logistics success [3].

\subsection{Influence of Information Flow Management on Firm Performance}

The study sought to investigate the relationship between information flow management and performance of Gas Depot in Yaounde Cameroon.

Table 3. Relationship between Information Flow management and Performance.

\begin{tabular}{llll}
\hline Performance & Coefficient & Std. Error & T \\
\hline Inventory Management & .000 & .161 & .003 \\
Constant & 3.840 & .633 & 6.063 \\
\hline
\end{tabular}

$\mathrm{F}=.000, \mathrm{P}>0.05, \mathrm{R}^{2}=0.000, \mathrm{R}^{2}$-Adjusted $=-0.026$

The value of variance $\mathrm{R}^{2}=0.000$, shows that $0 \%$ of the firms operating performance is explained by information flow management. The values of $\mathrm{F}=0.000, \mathrm{P}=0.998$, shows that information flow does not statistically and significant predicts the firms performance (i.e., the regression model is not a good fit of the data) and that information flow management does not significantly influence the performance of the Gas Depot in Yaounde Cameroon. The value of information flow is statistically significant $(\mathrm{t}=.003, \mathrm{p}=$ 0.998). The regression model explaining the results is given by: Perfprmance $=3.840+0.00 \times$ IFM

\section{Performance $=3.840$}

The model shows that information flow management doesn't affects the firm's performance, i.e. an increase in mean index of information flow does not increase the performance of the company by a positive unit mean index value. The influence of information flow management on the performance of Gas Depot was therefore examined.. Results of regression analysis show that information flow does not statistically significantly influence the performance of firms, $\mathrm{p}>0.05(\mathrm{P}=0.998)$ with an explanatory power of $0 \%$ percent. 
The model shows that information flow management doesn't affects the firm's performance, i.e. an increase in mean index of information flow management doesn't increases the performance percent.

The study sought to investigate the effect of information flow management on performance. Therefore, the null hypothesis "information flow management does not significantly influence the performance of manufacturing" was retained. Further the study established that information flow management does not practices internal information sharing, invested on information communication systems, achieves accurate demand forecasting, achieve timely respond to customer references, achieve optimal inventory, achieve smooth flow of materials and products, and use electronic customer feedback to a great extent across the Gas Depot in Yaounde Cameroon.

\section{Conclusion}

The study aimed to establish the influence of logistics Management dimensions on the performance of manufacturing firms. Additionally, the study sought to investigate the moderating influence of logistics information flow on the relationship between logistics management magnitudes and firm performance. The study established that two logistics management dimensions insignificantly influenced firm performance; only 1 did significantly influence the firm's performance which is Transport Management. This study provided evidence that inventory management, and information flow management are insignificantly and doesn't influence the performance of Gas Depot. This implies that an increase in performance of manufacturing firm is likely through embracing transport management practices within logistics management.

Logistics plays key role in supporting organization as they strive for more efficient management system [4] as in the business practices, the efficient logistic system together with the inefficient internal management would disable the organization to respond to the needs of the customers with the lowest price at the shortest feasible time frame including the quality level which does not meet customer expectation and would lead the organization to a competitive disadvantage situation against their rivals.

On Inventory management, the study established a significant negative relationship between inventory management and firm performance. A positive increase of transportation initiatives within the manufacturing processes increases the performance of firms. It is therefore concluded in the study that inventory management practices within the operations of the firm is insignificant on their performance. Information flow management was found to have an insignificant influence on the performance of Gas Depot. As a result, the study concludes that there is a negative relationship between information flow management and firm performance. On the other hand, the study confirmed that logistics information system moderate the relationship between logistics management practices and firm performance. In overall, logistics management was found to be collectively insignificantly influencing the performance of Gas Depot except for the case of transport management.

The researcher recommends that organizations should incorporate transport management in their operations processes such as proper fleet management, vehicle scheduling, route planning, proper maintenance of vehicles in other to ensure procurement of raw materials and distribution of products in order to increase overall cost efficiency, enhanced market share, and reduced lead time thereby impacting positively on their performance. Based on this study finding, the researcher recommended enough measures to be put in place to ensure there was continuous improvement in organizational performance in Gas Depot. The study also established that implementing transport and logistics practices led to incurring of additional costs. The study thus recommends that proper budgetary considerations and plans to be considered before undertaking any process as such. This will enable the determination of the advantages and the disadvantages of that particular process and thus assess its appropriateness. The study also recommends that Policies and legislation bodies should consider the need for facilitating and setting up policies which will enhance implementation process of logistics and transportation strategies in the firm.

To conclude, monitoring and evaluation of all the logistics and transportation practices is crucial to excellent operational performance at Gas Depot in Yaounde Cameroon.

\section{References}

[1] Atos, K. (2012). The elements of a successful logistics partnership: International Journal of Physical Distribution \& Logistics Management, 26 (3), 7-15.

[2] Bashir, M., Afzal, M. T., \& Azeem, M. (2008). Reliability and Validity of Qualitative and Operational Research Paradigm: Pakistan Journal of Qualitative and Operational Research, 4, (1), 35-45.

[3] Bowersox, D., Closs, D., and Cooper, B. M. (2007). Supply Chain Logistics Management. New York: McGraw Hill.

[4] Francis, G. H., andWaiganjo, E. (2014). Role of Supply Chain Practices on Customer Satisfaction in the Printing Industry in Cameroon: A Case Study of Morven Kester East Africa Limited. International Journal of Academic Research in Business and Social Sciences, 4 (10), 128-143.

[5] Fugate, B. S., Mentzer, J. T., and Stank, T. P. (2010). Logistics Performance: Efficiency, Effectiveness, and Differentiation. Journal of Business Logistics, 31 (1), 43-62.

[6] Ganotakis, P. \& Love, J. (2010). The Innovation Value Chain in New Technology Based Firms: Evidence from the UK. Journal of Product Innovation Management, 3 (4), 34-42.

[7] Gomes, C. F., Yasin, M. M., \& Lisboa, J. V. (2006). Key performance factors of manufacturing effective performance: the impact of customers and employees. The TQM Magazine, 18 (4), 323-40.

[8] Hausman, W. (2005). Global Logistics Indicators, Supply Chain Metrics, and Bilateral Trade Patterns. 
[9] Joppe, M. (2000). The Research Process. Fromhttp://www.ryerson.ca/ mjoppe/rp.htm

[10] J. S. \& Plank, R. E. (2009). Logistics performance measurement in the supply chain: a benchmark: benchmarking: An International Journal 16 (6), 785-798.

[11] Kenyon, G. N., and Meixell, M. J. (2007). Success Factors and Cost Management Strategies for Logistics Outsourcing. Journal of Management andMarketing Research, 7 (1), 1-17.

[12] Kilasi, L. B., Juma, D., \& Mathooko, P. M. (2013). The impact of Outsourcing of Logistics on the Competitive Advantage strategy of East African Breweries Limited: International Journal of Social Sciences and entrepreneurship 1 (3), 521-529.

[13] Liu, X., Grant, D. B., McKinnon, A. C. and Feng, Y. (2010). An empirical examination of the contribution of capabilities to the competitiveness of logistics service providers, a perspective from China: International Journal of Physical Distribution \& Logistics Management.

[14] Lynch, D. F., Keller, S. B., and Ozment, J. (2010). The Effects of Logistics Capabilities and Strategy on Firm Performance. Journal of Business Logistics, 21 (2), 47-68.

[15] Mentzer, J. T., andKonrad, B. P. (2017). An Efficiency/Effectiveness Approach to Logistics Performance. Journal of Business Logistics, 12 (1),
[16] Monette, D. R., Sullivan, T. J., \& DeJong, C. R. (2002) Applied Social Research. Orlando, FLA: Harcourt Press.

[17] Njambi, E. \& Katuse, P. (2013). Third party logistics in distribution efficiency delivery for competitive advantage in fast moving consumer goods companies in Kenya. International Journal of Social Sciences and Entrepreneurship $1(8), 15-27$.

[18] Prathap, G., \& Mittal, R. (2010). A performance index approach to library collection: Performance Measurement and Metrics11 (2), 259-65. Print.

[19] Richard, P. J., Devinney, T. M., and Yip, G. S., \& Johnson, G. (2009). Measuring Organizational Performance as a Dependent Variable: Towards Methodological Best Practice.

[20] Stevenson, M. \& Spring, M. (2009). Supply chain flexibility: an inter-firm empirical study International Journal of Operations \& Production Management.

[21] Tseng, Y-Y., Yue, W. L., \& Taylor, M. A., (2005). The Role of Transportation in Logistics Chain; Proceedings of the Eastern Asia Society for Transportation Studies.

[22] Tuttle, T. Heap, J. (2008). Green Productivity : Moving the Agenda: International Journal of Productivity and Performance Management 57, (1) 93-106. 